\title{
Multigene phylogenetic analysis redefines dung beetles relationships and classification (Coleoptera: Scarabaeidae: Scarabaeinae)
}

\author{
Sergei Tarasov ${ }^{*}$ and Dimitar Dimitrov
}

\begin{abstract}
Background: Dung beetles (subfamily Scarabaeinae) are popular model organisms in ecology and developmental biology, and for the last two decades they have experienced a systematics renaissance with the adoption of modern phylogenetic approaches. Within this period 16 key phylogenies and numerous additional studies with limited scope have been published, but higher-level relationships of this pivotal group of beetles remain contentious and current classifications contain many unnatural groupings. The present study provides a robust phylogenetic framework and a revised classification of dung beetles.

Results: We assembled the so far largest molecular dataset for dung beetles using sequences of 8 gene regions and 547 terminals including the outgroup taxa. This dataset was analyzed using Bayesian, maximum likelihood and parsimony approaches. In order to test the sensitivity of results to different analytical treatments, we evaluated alternative partitioning schemes based on secondary structure, domains and codon position. We assessed substitution models adequacy using Bayesian framework and used these results to exclude partitions where substitution models did not adequately depict the processes that generated the data. We show that exclusion of partitions that failed the model adequacy evaluation has a potential to improve phylogenetic inference, but efficient implementation of this approach on large datasets is problematic and awaits development of new computationally advanced software. In the class Insecta it is uncommon for the results of molecular phylogenetic analysis to lead to substantial changes in classification. However, the results presented here are congruent with recent morphological studies and support the largest change in dung beetle systematics for the last 50 years. Here we propose the revision of the concepts for the tribes Deltochilini (Canthonini), Dichotomiini and Coprini; additionally, we redefine the tribe Sisyphini. We provide and illustrate synapomorphies and diagnostic characters supporting the new concepts to facilitate diagnosability of the redefined tribes. As a result of the proposed changes a large number of genera previously assigned to these tribes are now left outside the redefined tribes and are treated as incertae sedis.
\end{abstract}

Conclusions: The present study redefines dung beetles classification and gives new insight into their phylogeny. It has broad implications for the systematics as well as for various ecological and evolutionary analyses in dung beetles.

Keywords: Dung beetles, Scarabaeinae, Scarabaeidae, Model adequacy, Classification, Molecular phylogeny

\footnotetext{
* Correspondence: sergxf@yandex.ru

Department of Research and Collections, Natural History Museum, University

of Oslo, P.O. Box 1172, Blindern NO-0318, Oslo, Norway
}

(c) The Author(s). 2016 Open Access This article is distributed under the terms of the Creative Commons Attribution 4.0 International License (http://creativecommons.org/licenses/by/4.0/), which permits unrestricted use, distribution, and reproduction in any medium, provided you give appropriate credit to the original author(s) and the source, provide a link to the Creative Commons license, and indicate if changes were made. The Creative Commons Public Domain Dedication waiver (http://creativecommons.org/publicdomain/zero/1.0/) applies to the data made available in this article, unless otherwise stated. 


\section{Background}

With over 6200 described species [1] and a global distribution, dung beetles of the subfamily Scarabaeinae (Coleoptera: Scarabaeidae) provide important ecosystem services [2]. They are one of the primary utilizers of mammalian dung on Earth and are historically one of the most recognized and best researched groups of beetles $[1,3-5]$. Recently, dung beetles have also become an established model group in ecology and developmental biology (e.g. [6, 7]). However, a robust classification and phylogenetic hypothesis for dung beetles is not available despite many recent phylogenetic efforts [1, 8-13]. As a result interpretation of their evolutionary, ecological and developmental features is often limited to select species and large scale comparative analyses are practically impossible.

The currently accepted classification splits the Scarabaeinae dung beetles into 12 tribes which, over the last two decades, have been the subject of 16 molecular- and morphology-based phylogenetic studies [1, 8-22]. These studies were reviewed in detail by $[1,7]$.

The results of most of these studies can be characterized by three common trends. 1) They resolve early branching clades or shallow nodes well, but intermediate nodes remain poorly resolved and/or weakly supported. 2) Seven tribes are always recovered as monophyletic or nearly monophyletic (e.g. Onthophagini, Oniticellini), while three tribes (Deltochilini, Ateuchini, and Coprini) are always polyphyletic. The polyphyletic tribes Deltochilini (=Canthonini) and Ateuchini (=Dichotomiini) together comprise ca. $55 \%$ of the total generic diversity in this group. Their highly polyphyletic concepts render the tribal classification in the entire subfamily extremely artificial. 3 ) The results of these key studies often propose conflicting hypotheses [1] leading to a lack of consensus on dung beetle evolutionary history.

One morphological [1] and two molecular phylogenies $[11,22]$ can be singled out due to their large taxon sample size and global biogeographic coverage; the rest of the studies are usually limited in these respects. The global morphological phylogeny of [1] comprises all main biogeographic and taxonomic lineages and provides an integrative pattern of phylogenetic relationships in dung beetles largely supported by previous publications. However, that study also stresses the need for more data, primarily molecular, to corroborate its findings.

The two available global molecular phylogenies [11] and [22] are similar in composition of genetic markers (COI, 16S, $28 S$ and COI, 16S, 28S, $12 S$ respectively) as well as species used. mtDNA markers are known to be saturated by fast evolution and not very informative about relationships above the species level, while the $16 S, 28 S$ and $12 S$ rDNA markers are challenging to align and analyze with traditional substitution models. These mitochondrial and rDNA genes are good candidates for resolving shallow divergences but they are less informative for recovering higher-level relationships [23] which calls for assembling larger datasets to improve the robustness of phylogenetic inference.

In this paper, we reconstruct the phylogeny of dung beetles using a molecular dataset that comprises 547 terminal taxa and 8 gene regions. This is the largest dung beetle molecular dataset assembled to date, and includes a large quantity of newly sequenced data. In addition, the present dataset has a global biogeographic coverage and incorporates major phylogenetic lineages and enigmatic taxa. To infer the phylogeny we employed a wide range of analytical approaches including direct optimization (POY), maximum likelihood (ML) and Bayesian inference (BI). The traditional substitution models used in modelbased methods (ML and BI) have been frequently shown to poorly reflect the reality of the evolutionary process [24, 25]; thus, their application can be inadequate for some molecular datasets. In this study, we explicitly test for model adequacy using Bayesian posterior assessment $[25,26]$ and perform partition selection based on the adequacy of the selected models. Although data selection guided by Bayesian posterior assessment allows inferring some meaningful relationships absent in datasets where it was not used, the results of both were generally similar. The efficient application of data selection using model adequacy assessment to large datasets, as the one used herein, is presently difficult due to the lack of computationally advanced software. We conclude that the development of such software can, in future, boost progress of Bayesian posterior assessment methods in phylogenetics.

Our results identify new lineages and corroborate some relationships inferred by earlier studies [1, 10-13, 19, 21]. The consistency of clades between the molecular phylogeny presented here and the most recent morphology based analyses [1] enables us to define new systematic concepts for the highly polyphyletic tribes Dichotomiini, Deltochilini and Coprini. Over the last half-century the concepts of these tribes have been constantly changing because clear synapomorphies which could ensure their unequivocal identification have always been missing. Given the principle of monophyly, we limit these tribes substantially to accommodate only those genera which are closely related to their respective type genera. We use the synapomorphies identified by the global morphological phylogeny of [1] to provide an effective identification of these tribes within their new definitions. Many genera hitherto considered members of these tribes are now excluded from them. We treat those genera as incertae sedis and discuss the necessary steps towards their phylogenybased classification. We also expand the concept of the tribe Sisyphini by adding the genus Epirinus that was previously placed in Deltochilini. 


\section{Methods}

\section{Taxon sample and vouchers}

A total of 530 specimens of dung beetles (Scarabaeinae) belonging to 137 genera from all 12 tribes and biogeographic regions were sampled. 95 specimens from 72 species were sequenced specifically for this study. Representatives of the following dung beetle genera are sequenced for the first time: Haroldius, Canthonella, Cryptocanthon, Homocopris, Leotrichillum, Paracanthon, Paraphytus, Scatimus, Tesserodoniella, and Trichillidum. The outgroup comprised 17 terminals belonging to 10 genera from the Scarabaeidae subfamilies Chironinae, Aegialiinae and Aphodiinae which are closest relatives of Scarabaeinae based on previous studies [27-31]. Accession numbers and other relevant vouchers information is summarized in Additional file 1: Table S1. In all figures, tables, and Additional files, specimens sequenced for this study are marked with * next to their species names. List of genera with author citations is given in Additional file 2: Table S2.

In this study the tribal classification for genera follows [7]; nomenclature for family-group names follows [32] and [33]. Along with traditional concepts for some tribes in the discussion we also propose newly circumscribed concepts, which are marked as sensu novo. The name Ateuchini is used according to [32] to address genera conventionally treated as Dichotomiini (see also "Changes in classification" section) and the name Deltochilini is used as a senior synonym for Canthonini [32].

The voucher specimens used in this study are deposited as indicated in Additional file 1: Table S1. Abbreviations used in the tables are as follows:

CEMT: Seção de Entomologia da Coleção Zoológica, Departamento de Biologia e Zoologia, Universidade Federal de Mato Grosso, Cuiabá, Brasil (F. Vaz-de-Mello). UPSA University of Pretoria, Insect collection (C.

Deschodt and C. Scholtz).

ZMUC Natural History Museum of Denmark (A.

Solodovnikov and S. Selvantharan).

CNCI Canadian National Collection of Insects, Arachnids and Nematodes, Ottawa (V. Grebennikov and B. Gill). ABTS Andrew Smith private collection, Canada, Ottawa. NZAC New Zealand Arthropod Collection, Auckland (R. Leschen and S. Forgie) ZMUN Natural History Museum, Oslo, Norway (V. Gusarov).

ANIC Australian National Insect Collection, Australian Capital Territory, Canberra City, CSIRO, (C. Lemann and T. Weir)

\section{Molecular markers}

We used 8 phylogenetically informative markers: $16 \mathrm{~S}$ ribosomal RNA (16S), 18 s ribosomal RNA (18S), $28 \mathrm{~S}$ ribosomal RNA domain 2 (28SD2), 28 s ribosomal RNA domain 3 (28SD3), cytochrome c oxidase I (COI), carbamoylphosphate synthethase $(C A D)$, topoisomerase I (TP1) and wingless (Wg). Mitochondrial (both rDNA and protein encoding) and the nuclear rDNA genes have been widely used in previous studies of dung beetles $[11-13,18-21]$ and represent the bulk of data for this group in GenBank. Only three phylogenetic studies focused on Africa and Madagascar have used nuclear protein-coding genes $C A D$ and/or $T P 1$ [12, 21, 34]. In this study, we use the nuclear gene $W g$ for the first time in a dung beetle study along with the rDNA regions (18S, 28SD2, 28SD3) and CAD, TP1. We combine our new sequence data with the data from the same markers available in GenBank (total: 547 terminals, alignment length $5837 \mathrm{bp)}$ to address higher-level relationships of dung beetles (Additional file 3: Matrix S1) .

\section{DNA extraction, PCR amplification, and sequencing}

Genomic DNA was extracted from the head and/or prothorax or legs, following the Qiagen DNeasy Blood \& Tissue Kit (QIAGEN) tissue protocol. PCR follows [35] with the following modifications: the reaction was performed in a $20 \mu \mathrm{L}$ reaction volume using, $0.5 \mu \mathrm{M}$ of each primer, $10 \mu \mathrm{L}$ AmpliTaq Gold, Master Mix (Applied Biosystems), and $3 \mu \mathrm{L}$ of the respective genomic DNA extract. If target genes were difficult to amplify $0.4 \mu \mathrm{g}$ Bovine Serum Albumin (BSA) were added. The general PCR profile consisted of an initial denaturation step at $94{ }^{\circ} \mathrm{C}$ for $2 \mathrm{~min}$, followed by 30 cycles at $94{ }^{\circ} \mathrm{C}$ for $1 \mathrm{~min}, 52-68{ }^{\circ} \mathrm{C}$ for $30 \mathrm{~s}$, and $72{ }^{\circ} \mathrm{C}$ for $1-2 \mathrm{~min}$, and a final extension step of $10 \mathrm{~min}$ at $72{ }^{\circ} \mathrm{C}$. The annealing temperature was optimized separately for each pair of primers. TP1, CAD, $W g$ were amplified using the nested PCR approach described by [36]. All primers used for amplification and amplification strategies are listed in Additional file 4: Table S3. The PCR products were purified with ExoSAP-IT (Stratagene), and then sequenced. All fragments were sequenced in both directions. The GenBank accession numbers of the sequences are given in Additional file 1: Table S1.

\section{Sequence alignment and secondary structure prediction}

The sequences were managed, edited and assembled into contigs, and the contigs arranged into the final datasets in Geneious version R6 [37].

For the phylogenetic analyses, alignments were performed with the web-based version of MAFFT [38] (http://mafft.cbrc.jp/alignment/software/) using Q-INS-i option, that takes into account secondary structure, for rDNA genes with less than 300 sequences $(18 S, 28 S D 2)$, and L-INS-i for the rest. The secondary structure for 
rDNA genes was reconstructed in RNAalifold [39] based on the alignments obtained from MAFFT.

Simultaneous alignment and structure prediction for Bayesian model adequacy assessment was performed using LocArna [40]. The size of datasets that can be operated by LocArna is limited to 30 sequences which make this method inapplicable for large phylogenetic analyses. In order to make computations feasible we reduced the dataset by randomly selecting a set of 30 sequences of each gene for model adequacy analyses to fit LocArna requirements. Simultaneous reconstruction and alignment in LocArna better fits our purpose for the detailed exploration of partitions despite the necessary dataset reduction.

\section{Selection of sites, sequences and partitioning Site and sequence selection}

The $3^{\text {rd }}$ codon positions of $C O I$ were excluded from all analyses (hereafter addressed as the dataset "ALL") as they have been suggested to suffer saturation for deep divergences which can potentially bias phylogenetic analyses (e.g., [41, 42]). For some analyses, sites containing gaps in more than $20 \%$ of the sequences were also removed (dataset "G20"). The value of $20 \%$ was found empirically as an optimal trade-off between removing gaprich sites capable of potentially introducing noise and, at the same time, keeping a sufficient amount of the original sites for the phylogenetic inference. Finally, for the last set of analyses, in addition to the previously removed sites, we also removed the six partitions which yielded low $\mathrm{p}$-values in Bayesian posterior prediction (dataset "DT3", see Results: Model adequacy section). In total all datasets comprised $\sim 40 \%$ of missing data due to incomplete sequencing, their alignment lengths were 5838 bp, 4775 bp and 4016 bp for ALL, G20 and DT3 datasets respectively.

In order to test sensitivity of the incomplete sequencing, we also composed two reduced datasets consisting of species for which at least 4 and 5 genes were assembled (244 and 77 species respectively). Each reduced dataset was also analyzed using maximum likelihood method with different portions of sites excluded (i.e. ALL, G20 and DT3).

\section{Partitioning}

Initially, the entire dataset was split into 28 a priori data blocks. This was done based on the secondary structure (loops and stems regions) for each rDNA gene and based on domain structure and codon position for each protein-coding gene. The domain structure was obtained from InterPro database [43, 44] using Geneious InterProScan plugin v. 1.0.6.

We used Partition Finder [45] under Bayesian Information Criterion (BIC) and the greedy algorithm option in order to find the best partitioning scheme and models. To partition the data for the phylogenetic analyses, we ran Partition Finder on the dataset from the MAFFT analysis using the 28 a priori data blocks and 200 randomly selected sequences to reduce computational time. The searches were performed on the set of models implemented in MrBayes excluding a subset of invariant site models, as using the invariant site and the gamma parameter at the same time is not advisable ([46], the RAxML v8.1.X Manual).

Partition Finder analyses of the 28 a priori data blocks (run \#1) found best partitioning scheme comprising 19 partitions (536 parameters, $\mathrm{BIC}=192851.786103$ ). In this scheme, loop and stem region of rDNA genes were placed in a separate partition whereas protein-coding genes were partitioned by codon position and gene. Since this partitions number was still high and could result in computational issues, we manually partitioned the rDNA genes in only two partitions (stem and loop regions) and concatenated some partitions of the protein coding genes mainly based on codon positions. This reduced the number of partitions from the 19 inferred partitions to 10. Partition Finder was run again (run \#2) on the data set with 10 partitions resulting in a better BIC score (487 parameters, $\mathrm{BIC}=163834.428304)$ and a scheme retaining the 10 partitions as initially set (Additional file 5: Table S4). The failure of Partition Finder to find the 10-partition scheme from the beginning (or any better partitioning than the proposed 19 partitions) is likely a shortcoming of the greedy algorithm. The scheme from run\#2 and the one with the best BIC score were used in the ML analyses.

In the tests of model adequacy, the Partition Finder was run separately for each gene on its respective $a$ priori data blocks from the LocArna alignment results.

\section{Model adequacy assessment}

The model adequacy assessment on big datasets, as the one used in the present study, is limited by the software capacity designed for such analyses and the lack of necessary computational pipelines. Thus, as a proxy to model adequacy, we randomly selected a set of 30 sequences for each gene (see Sequence alignment section). Each gene aligned in LocArna was then split into its $a$ priori data blocks and run separately in Partition Finder to test for the best partitioning scheme and models (Additional file 6: Table S5). To test models adequacy we used Bayesian posterior assessment (BPA) as implemented in PuMA [47]. Each inferred partition, after excluding sites containing gaps (since PuMA cannot handle gaps) was separately analyzed in MrBayes (see Maximum likelihood and Bayesian inference section) to sample parameters from the posterior distribution. The sampled parameters were used to perform 
BPA in order to test whether the selected model can adequately capture the process which generated the analyzed sequences.

\section{Maximum Likelihood (ML) and Bayesian Inference (BI)} Both BI and ML analyses were run on the High Performance Computing cluster Abel at USIT, the University of Oslo.

\section{$M L$}

The ML analyses were run in RAxML version 8.0.26 [46] using the three different datasets ALL, G20 and DT3 and the partitioning scheme from Partition Finder run\#2 (Additional file 5: Table S4, and Site selection and partitioning section). We used $-f a$ option to perform rapid Bootstrap analysis (1000 replicates) and search for best scoring ML tree in one program run the GTRCATX model ( $-m$ GTRCATX) applied to each partition; the final tree was evaluated under GTRGAMMA model.

\section{$B I$}

For the purpose of testing model adequacy, we ran MrBayes using the default priors and the following options: ngen $=5 \mathrm{M}$, samplefreq $=5 \mathrm{~K}$, nchains $=4$, and temp $=0.2$.

Bayesian phylogenetic inference was performed in MrBayes version 3.2.2. [48] and ExaBayes version 1.4.1 [49] using ALL, G20 and DT3 datasets. Both programmes MrBayes and ExaBayes use similar analytical procedure. ExaBayes in contrast to MrBayes implements only GTR models and exponential prior for branch length (unlike compound Dirichlet priors in MrBayes). At the same time, ExaBayes provides advanced parallelization and computational techniques that significantly speed up computations in comparison to MrBayes.

For the actual phylogenetic analyses, we ran MrBayes with default priors except for the branch length. The default exponential branch length prior is known to cause bias in the branch length estimates in partitioned datasets $[50,51]$. We used the compound Dirichlet prior instead as suggested by [52] and [51]. The full description of the analysis set-up is provided in the Additional file 7.

In ExaBayes we ran only unpartitioned analyses under the GTR model to avoid biased estimation of branch length due to the use of exponential branch length prior in partitioned data [50, 51]. For each dataset (G20 and DT3) the two runs in ExaBayes were ran with default priors and one heated chain (heatFactor 0.3) for $100 \mathrm{M}$ generations, sampling parameters every $1000^{\text {th }}$ generation. The two runs converged after $50 \mathrm{M}$ which were discarded as burn in. Sdsf between the runs dropped below the acceptable value of $5 \%$ being 0.022 and 0.018 for G20 and DT3 dataset respectively.

\section{Direct optimization (POY)}

For the direct optimization analyses protein coding genes were treated as preealigned while ribosomal genes were split into homologous regions based on amplicon limits and preliminary MAFFT alignments. This procedure was necessary because many sequences were missing some of the amplicons or had areas with poor quality that were excluded in the process of sequence editing, resulting in length variation that is not due to insertions/deletions. Limits of different regions were marked with \# and matrices were analyzed under maximum parsimony direct optimization. Direct optimization analyses were carried out in the computer program POY v 5.1.1b [53]. We used a search strategy based on iterated timed searches (multiple Wagner trees followed by SPR + TBR + ratchet and tree fusing) for 4-6 h as described in [54]. The strategy uses a series of timed searches that take, as an input, the best tree from the previous round until results stabilize and further iterations consistently find the same trees. There are large numbers of potential combinations of insertion/deletion, gap extension and substitution costs that can be explored in POY. Here we selected a limited number of parameter schemes that have been shown to perform optimally in other studies or have been suggested as best on philosophical grounds. For example the parameter set 3221 (indel opening cost $=3$; indel extension $\operatorname{cost}=1$; transversions $=$ transitions $=2$ ), was suggested as best using philosophical reasoning by J De Laet [55]. The parameter sets investigated were: 111, 121, 211, 221, 3221 and 3211.

\section{Results}

\section{Model adequacy}

Results from the assessment of model adequacy are summarized in Fig. 1. The posterior predictive $p$-values for the majority of the partitions fall within the $95 \%$ confidence interval (Fig. 1, red circles) indicating that models used to analyze these data adequately capture (to a certain extent) the process of their evolution. For this analysis the highest model adequacy corresponds to partitions with p-value approaching 0.5 whereas the models with extremely high or low values in this twotailed test should be rejected. Interestingly, all rDNA genes demonstrate $p$-values that were not significantly different from our null-model and $18 S$ shows the best performance amongst all markers used in the present study. Unreasonable model specifications were found only in some protein-coding genes partitions, with TP1 generally showing the worst scores ( $p$-values $<0.05$, Fig. 1, blue circles).

\section{Phylogenetic analyses}

The full and two reduced datasets of at least 4 and 5 genes (e.g. Additional files 8 and 9: Tree S12-13) yielded 




Fig. 1 Partitions and model adequacy assessment. Left graph shows per partition $p$-values for every gene. The $p$-values test a null hypothesis that model applied to partition is adequate based on multinomial test statistics in PuMA (histogram for the 165 gene on the top exemplifies multinomial test statistics). Partitions with values within the $95 \%$ two-tailed confidence interval are shown with red circles (null hypotheses is supported), while those with values outside the tails of the distribution are blue circles (they are excluded from dataset DT3). P-value approaching 0.5 correspond to highest model adequacy. Partitions consist of a priori data blocks based on secondary structure (rDNA genes), codon position (COI and Wg) or codon position and domain structure (CAD, Tp1). In data blocks names the capital letter corresponds to domain (shown on the right) while number indicate codon position. Additional information and domain names are given in Additional file 6: Table S5

similar topologies and support values but the reduced datasets did not recover some well-corroborated groups found here and in previous studies as they were lacking more than $50 \%$ of terminals present in full dataset. Given the significance of taxon sample size in assessing global phylogeny, we limit our discussion below only to the datasets based on the full taxon sample.

All datasets (ALL, G20, DT3) analyzed using ML produced congruent topologies that differed mainly in linkage of intermediate branches (Figs. 2, 3, Additional files 10, 11 and 12: Tree S1-3). The percentage of shared clades between any two of three datasets was high (ALL \& $\mathrm{G} 20=74.9 \%$, ALL \& DT3 $=72.5 \%$, G20 \& DT3 $=$ 75.8\%, Additional file 13: Table S7).

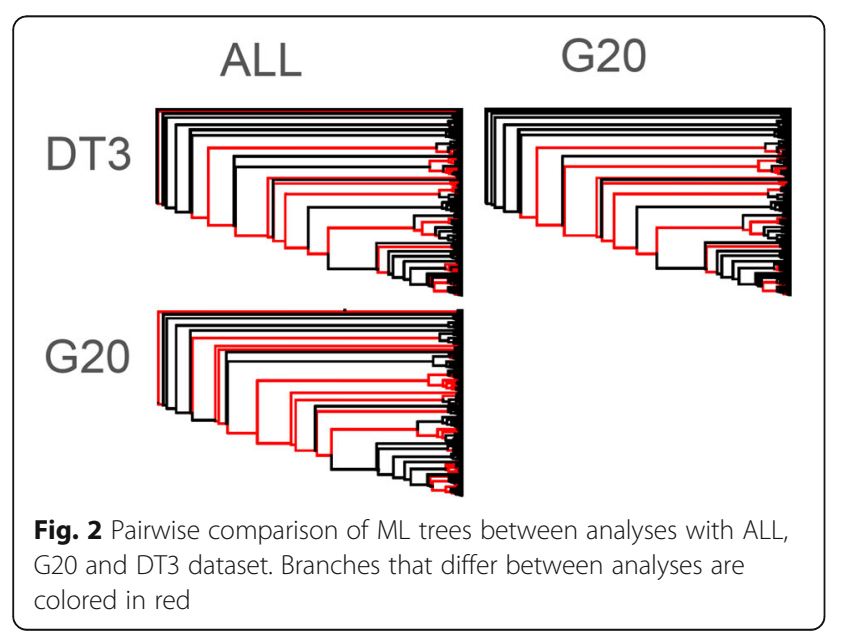

The results from the MrBayes analyses were not satisfactory - standard deviation of split frequencies (0.077) was higher the acceptable value of 0.05 . Nevertheless, the inferred consensus tree can be, to certain extent, considered stable (see Additional file 7 for more details). Poor convergence in MrBayes is known to occur when analyzing big datasets $[56,57]$ due to ineffective MCMC sampling from the posterior distribution of topologies [58].

Despite the BI convergence issues, results from ML and BI analyses were generally also congruent (percentage of shared clades with any of three ML analyses ranges from $71.1 \%$ up to $75.5 \%$, Additional file 13: Table S7). However, the partitioned Bayesian analysis in MrBayes (Additional files 14 and 15: Tree S4, S5) was more similar to the ML topologies when compared with the unpartitioned analysis from ExaBayes. Because of this higher incongruence and less reasonable partitioning scheme (single partition) we do not overview the ExaBayes results in detail. The partitioned Bayesian analysis is also congruent to ML results in terms of support for intermediate branches, many of which are unresolved in the Bayesian consensus tree from the partitioned analysis and vary among ML analyses depending on the dataset. At the same time, both ML and BI trees were drastically different from the POY trees (Additional files 16, 17, 18, 19, 20 and 21: Tree S6-S11). POY yielded trees with many genera and well-supported monophyletic groups appearing as polyphyletic. Because results from POY were highly divergent from any other published phylogeny and from ML and BI 


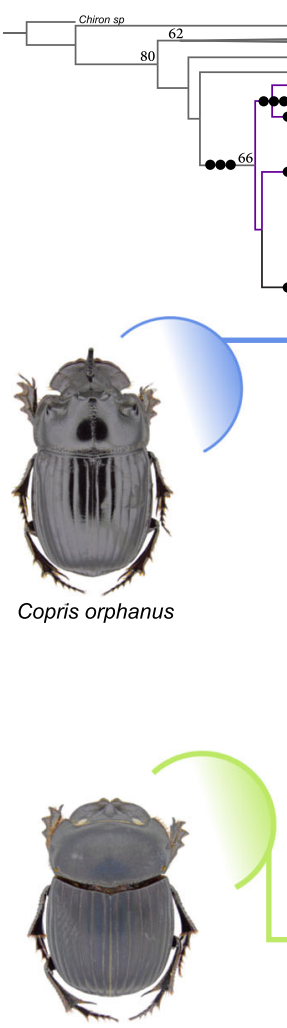

Dichotomius sericeus



Malagoniella astyanax



$\mathrm{O}_{\mathrm{O} I \mathrm{~B}}$

All G20 B

- similar node composition

Clade (A)
Outgroup:

Chironinae, Aegialiinae, Aphodiinae

Sarophorus, Coptorhina,

Odontoloma Endroedyolus, Peckolus.

(1)

....'Haroldius

Byrmidium, Dicranocara, Namakwanus

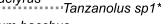

Scarabaeini

"basal Scarabaeinae"

\section{Pedaria}

Coprini sensu novo

Apotolamprus, Nanos

Gyronotus

Australasian

endemic genera

Uroxys, Bdelyropsis

Ateuchini: Scatimina partim

Trichilum, Trichililidium, Leotrichillum . .

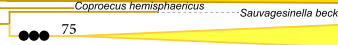

Trichill

.... Scatimus erinnyos*

Arachnodes Cryptocanthon

canthidium .............. Dichotomiini sensu novo

Phanaeini A.......Ateuchini partim

Eucranini

Deltochilini (Canthonini) sensu novo

Catharsius

Metacatharsius

Gymnopleurini

Anachalcos

hon, Epactoides, Madaphacosoma

Eurysternini

Sisyphus, Neosisyphys Sisyphini

Epirinus $\quad$ sensu novo

Aphengoecus

................... Pycnopanelus

Macroderes

Xinidium

Onitini



Onthophagini,

Oniticellini

Fig. 3 (See legend on next page.) 
(See figure on previous page.)

Fig. 3 Maximum likelihood tree of Scarabaeinae. ML tree of 547 Scarabaeinae terminals and outgroup. The tree shown here is from the analyses of the DT3 dataset. Black and grey circles mapped onto branches of this tree indicate presence/absence of node (clade) in ML analyses with ALL and G20 datasets as well as Bayesian analysis (BI). Similar but not identical node (clade) composition is marked with * above black circle. The majority of terminals are cartooned based on taxonomy, with the size of the cone corresponding to the number of analyzed terminals. The color of braches is used for readability purpose. Values above branches indicate bootstrap support that is shown only if value $>50 \%$. Representative taxa are shown for the revised tribes discussed in this study

analyses performed here (see Results) we did not continue with further exploration of the results under direct optimization.

Since all ML and BI (in MrBayes) analyses are similar, for illustration purposes we select the ML analysis of the DT3 dataset as a base topology. This is also the dataset with the highest number of inadequate partitions excluded. Then, in order to summarize the results from the other two datasets and the congruence among analyses, we mapped the same clades onto the DT3 tree (Fig. 3, Additional file 12: Tree S3). The differences and similarities in major lineages among the analyses are further summarized in a greater detail in Additional file 22: Table S8.

Monophyly of Scarabaeinae was supported by all ML and BI analyses. Also, all ML analyses recover "basal Scarabaeinae" as paraphyletic lineage whose side branch leads to all the remaining Scarabaeinae. Almost all genera were recovered monophyletic with just a few of them (i.e. Heliocopris, Tanzanolus, Janssensantus, Boletoscapter, Arachnodes, Canthidium, and Frankebergerius) polyor para-phyletic depending on the dataset analyzed.

The majority of tribes in their conventional definitions emerge monophyletic except for Oniticellini that is nested within Onthophagini, and the highly dispersed Deltochilini, Ateuchini (Dichotomiini) and Coprini. For the latter three tribes new concepts are established (see Systematic entomology section).

In our phylogeny, Paraphytus and Haroldius are placed within the basal Scarabaeinae: the most basal taxon Paraphytus is sister to Sarrophorus-like genera, while Haroldius is a sister to Byrrhidium + Dicranocara + Namakwanus clade. African Pedaria comes up as sister to Copris + Litocopris (Fig. 3).

The endemic Madagascan genera formerly treated as Deltochilini split into four lineages that are spread across the tree: (i) genera Apotolamprus + Nanos form a separate clade (ii) genus Epactoides emerges in the same clade with Oriental Ochicanthon and Afro-Madagascan Madaphacosoma (ii) Arachnodes comes up monophyletic in results of the G20 dataset while it is polyphyletic in results based on the DT3 dataset and (iv) genus Cambefortantus forms a separate lineage; in results from the G20 dataset it is sister to the Australian Boletoscapter.

In ML analyses, all Australasian endemic genera except Boletoscapter tended to form a paraphyletic lineage with the Neotropical genera Uroxys + Bdelyropsis nested within it.

The neotropical tribe Eurysternini is sister to the AfroMadagascan-Oriental clade formed by the genera Madaphacosoma, Ochicanthon and Epactoides. A large monophyletic group (clade A) is composed of taxa with primarily Old World origin (e.g. [59, 60]). It includes the tribes Onitini, Onthophagini, Oniticellini along with the genera Xinidium, Macroderes, Hammondantus and Pycnopanelus.

South African deltochiline-like Epirinus is recovered as sister to the primarily Old World genera Neosisyphus and Sisiphus traditionally assigned in the tribe Sisyphini.

The American tribes Phanaeini and Eucranini are recovered as monophyletic and sister to the other American genera from the tribe Ateuchini/Dichotomiini (namely, Canthidium, Dichotomius and Ateuchus).

The neotropical Ateuchini subtribe Scatimina [61] splits into two lineages, one includes the genera Trichillum, Trichillidium and Leotrichillum and the other is comprised by Scatimus. However, the ML analysis of the ALL dataset and both Bayesian analyses supports sister relationship between Scatimus and Ateuchus.

Only DT3 dataset recovered monophyly of genera Canthidium, Heliocopris and Frankebergerius and close relationships between Homocopris and Ontherus.

Some noteworthy groups were not recovered in the DT3 and ALL datasets; however, they were recovered by the ML analyses of the less data restrictive G20 dataset. A clade including the Neotropical genera Tesserodoniella, Homocopris, and Paracanthon was resolved. The African genus Gyronotus appears as a close relative of the African clade Anachalcos + Canthodimorpha. Finally the Neotropical Canthonella was nested within Australasian endemics clade.

\section{Discussion}

Data, model adequacy and partitions Bayesian Posterior Assessment (BPA)

The traditional model selection procedure in phylogenetics focuses on selecting the best model from a set of substitution models using statistical criteria such as AIC, BIC, Bayes factor, etc. However, this procedure does not guarantee that the selected model can be reasonably applied to the data due to factors such as heterogeneous evolutionary rates or selection, which can violate 
assumptions of the available substitution models. Use of substitution models that do not adequately capture the evolutionary processes in the data may in turn result in biased phylogenies. It has been suggested that testing for model adequacy should be an important step in phylogenetic analysis, although it remains poorly explored and rarely implemented $[25,26]$.

One of the ways to test the model adequacy is to use posterior predictive assessment (BPA) in a Bayesian framework [25, 26, 62, 63]. The BPA applied, in this study [47], uses a sample of parameters from the posterior distribution of the Bayesian analyses to simulate molecular datasets and then, assesses the probability of seeing the original dataset in the array of the simulated ones based on the multinomial likelihood test statistics. Our results show that not all molecular partitions that we initially designed were adequate in BPA framework (e.g., TP1). Use of such datasets or data partitions with available substitution models (even with the models found to fit the data best under AIC or BIC for example) do not adequately capture the process that generated the data and may lead to biased results.

We also show that BPA performance substantially differs between codon and domain position in proteincoding genes. While some parts of these genes can be adequately analyzed with the traditional phylogenetics models, others may have to be excluded from phylogenetic analyses. This finding further stresses the need for choosing an appropriate partitioning scheme and assessment of model adequacy prior to the phylogeny estimation.

All ML and BI analyses produced similar topologies sharing $71-75 \%$ of identical clades (Additional file 13: Table S7). The analyses including partitions that performed poorly under the BPA test (ALL and G20) did not differ significantly from the results of the DT3 dataset that excludes all partitions that did not pass the BPA test. This points to a strong phylogenetic signal in the part of the data where substitution models did perform plausibly.

Selecting and testing data using BPA has a statistically solid basis $[25,26,62,63]$ and brings a great potential to improve phylogenetic inference. However the current implementation of this approach to big datasets, as the one used here, is problematic due to the lack of software capable to perform efficient computations on big datasets. The large size of our dataset did not allow implementing BPA analysis in a Bayesian framework under partitioned scheme (in MrBayes for example). The alternative program ExaBayes, that provides high level of parallelization and computational speed, is currently lacking a proper conjugate prior (e.g. compound Dirichlet prior) for tree branch length, which may bias the analyses when using data partitioning. Thus, at present, large datasets can be efficiently analyzed only in ML framework using RaxML program that uses exclusively GTR model for phylogenetic inference, thereby providing a limited model choice for the inference and BPA procedure.

\section{Partition scheme search}

In addition to use of BPA as a tool to evaluate data and model performance we also used the program Partition Finder in order to select optimal partition scheme for the analyses. Here we used the program following the manual recommendations, i.e. providing an initial set of partitions and letting the algorithm find the best partitioning scheme. However, we found that this procedure may not necessarily find the best solution (as measured by BIC score). We show that, at least in the present case, it is possible to further improve partition schemes by manually altering the results from Partition Finder. Identification of the reason for this behavior was beyond the scope of this study, although it is presumably due to the use of the greedy algorithm option. Therefore, we strongly encourage researchers relying on this algorithm to follow a procedure as the one outlined in the Methods section.

\section{Dung beetles higher level relationships Trees and analyses}

Many of the clades supported by the present phylogeny are consistent with previous phylogenetic treatments of dung beetles [10-13, 19, 21]; and, the present results are also highly congruent with the global morphological phylogeny [1]. This similarity between studies shows that results from different sources tend to converge on an underlying pattern in enlarged datasets. The differences across datasets and ML and BI analyses were insignificant in the context of higher-level relationships. Exclusion and inclusion of different partitions had its advantages and disadvantages; some meaningful relationships inferred in the first case were absent in the second and vice versa. This is likely a result of the heterogeneous nature of the evolutionary process that influences the performance of a marker across a given tree. Although the excluded partitions are found by the BPA as inflicting potential bias on phylogenetic inference, they can be locally informative, especially in resolving recent divergences. The exclusion of these partitions may result in data deficiency at that level and decreased resolution for shallow nodes.

POY trees show significant differences from ML and BI trees and all other published phylogenies. We hypothesize, that this odd behavior of POY in the present study is probably result of the large portion of missing data $(\sim 40 \%)$, which negatively affects the direct optimization method. 


\section{Molecules vs. Morphology}

The position of "basal Scarabeinae" with Paraphytus, as was initially predicted by morphology $[1,10]$, is largely congruent with present molecular results. The position of Haroldius as sister to Byrrhidium + Dicranocara + Namakwanus within "basal Scarabaeinae" is surprising but strongly supported (see bootstrap values for the preceding ancestor nodes). The phylogenetic affiliations of Haroldius have long remained enigmatic: preliminary morphological analysis placed it in Onthophagini [64], while other authors placed it within Deltochilini [65].

The Australasian clade found here is similar to that supported by morphological analysis (clade Aus1, Fig. 6 in [1]), although in both cases endemic Australasian genera do not form a strictly monophyletic group. Interestingly, morphology, unlike molecules, strongly supports Australian Boletoscapter within Australasian clade (Aus1 in [1]); whereas this study recovers neotropical Uroxys + Bdelyropsys nested within Australasian clade. Alternatively, another molecular [22] phylogeny suggests sister relationships between Uroxys + Bdelyropsys and Boletoscapter but does not support such Australasian clade. African Pedaria, having significant morphological similarities was recovered within Aus1 by morphology [1] and a previous molecular study [11]; however, in the present study it is placed as a sister of Coprini sensu novo.

In this study, clade A, comprising some taxa of Old World origin, is moderately supported and biogeographically well defined. In morphology, this clade is split into three remotely related lineages (arrowed clade, part of L2 and K1, Fig. 6 in [1]). It is noteworthy that morphological analyses $[1,10]$ did not support a sister or close relationship between Onitini and Onthophagini + Oniticellini, which is recovered by molecular phylogenies $($ e.g. $[8,11])$ including the present study. A lack of synapomorphies that would support this grouping in the morphological dataset is likely the cause for this incongruence.

Madagascan Apotolamprus and Arachnodes form a clade in the morphological phylogeny (clade G1, Fig. 6 in [1]) due to their significant similarities; however, in the present study they appear to not be closely related, which confirms the results of other molecular study [13].

The relationship between the Ateuchini type genus Ateuchus and the Ateuchini subtribe Scatimina varies depending on the dataset. The present molecular data suggests that the subtribe Scatimina may be polyphyletic as it is split into two groups Trichillum + allied genera and Scatimus. Scatimus shows close relationship to Ateuchus but that is not the case for the clade including Trichillum + allied genera. This contradicts two morphological phylogenies $[1,10]$, which recover the monophyly of Ateuchus + Scatimina, although it is supported only by one homoplastic synapomorphy - presence of trochantofemoral pit [1].
The present results along with previous morphological [1] and molecular [66] studies support the position of deltochiline-like Epirinus within the tribe Sisyphini. Based on these results, here we place Epirinus in the tribe Sisyphini sensu novo. Further arguments for that decision are provided in the "Changes in classification" section below.

The congruence between results from previous molecular analyses [11-13, 19-22], recent morphological analysis $[1,10,15]$ and the molecular analysis presented here for the tribes Deltochilini, Ateuchini and Coprini as well as the high support for the sister relationships between Epirinus and Sisyphini motivated us to reevaluate the limits of these tribes.

\section{New tribal concepts and perspectives for new classification}

Natural tribal classification for dung beetles is essential to study their diversity, ecology and evolution. Strong polyphyly of some historic tribes found in the present analyses and in previous phylogenies [1,11-13, 19-22] indicates that the tribal classification as currently defined does not reflect natural units and has to be revised.

Systematic classification must fulfill two main purposes (i) classify the diversity under study into monophyletic units reflecting their evolutionary history and (ii) provide characters that allow unambiguous diagnosability of all included taxa. Given that requirements for monophyly and diagnosability must be fulfilled, splitting a phylogenetic tree into groups (e.g. tribes) is a somewhat subjective procedure - groups can be defined at shallower nodes producing many monophyletic lineages with few terminal taxa or at deeper nodes resulting in fewer groups that include more terminal taxa. In order to comply with the aforementioned classification purposes, the scarabaeine tribes seem to be better defined at more terminal nodes resulting in a somewhat larger number of tribes. At that level molecular and morphological phylogenies are largely congruent and clades are defined by large numbers of synapomorphies. These two properties guarantee wellsupported monophyly and efficient identification for the resulting groups. Contrary to that, defining groups at deeper nodes would yield fewer poorly corroborated tribes that are hard to diagnose, because at this level nodes are often supported by single homoplastic synapomorphy. Thus, splitting and not lumping seems to be an efficient way for the development of a new higher level dung beetle classification due to the lack of diagnosability at deeper nodes. Although, in our results some intermediate nodes are still poorly supported, they are irrelevant for the development of new classification as they lack diagnosability in the context of morphology. 
Traditional concepts [7] for the tribes Deltochilini, Ateuchini (Dichotomiini) and Coprini render them largely polyphyletic. The results presented here and in the recent morphological phylogeny [1] are consistent in supporting the monophyly of the clades that contain the type genera of those tribes (or tribes considered their synonyms) and their close relatives providing a solid basis for the revision of these tribal concepts (a special case of Coprini is discussed below). Moreover, global morphological analysis [1] identified synapomorphies that allow easy identification and diagnosis of these revised tribes. Until now identification of many dung beetle tribes has been practically impossible because traditional concepts were not based on synapomorphies or diagnostic characters but rather used authors' intuition and overall habitus similarity. Explicit concepts and clear characters defining the revised tribal definitions presented here contribute to the stability of the dung beetle classification. However, at the same time they leave 101 genera, previously placed in Ateuchini (Dichotomiini), Deltochilini and Coprini, without tribal affiliation (incertae sedis, Additional file 23: Table S9). Many of these incertae sedis genera cannot be placed easily in other existing tribes (Fig. 3) and it is possible that new taxa will have to be defined in order to accommodate them.

We also propose to expand the concept for the tribe Sisyphini. Sisyphini traditionally comprised only three genera. Both molecular and morphological analyses support sister relationship between the traditional Sisyphini genera and the South African genus Epirinus that was formerly placed within the tribe Deltochilini. Monophyly of this new group is supported by three synapomorphies and by high bootstrap and posterior probability in the corresponding analyses. Based on this evidence we propose to transfer Epirinus in Sisyphini.

\section{Changes in classification Tribal concepts}

The new limits (sensu novo) for tribes proposed here are based on the present results and are also supported by the findings from several recent molecular phylogenetic analyses [11-13, 19-22] and on the global morphological phylogeny [1]. The traditional concepts for the tribe Dichotomiini, Deltochilini (Canthonini), Coprini and Sisyphini follow [7]. List of genera included in the new concept of each tribe (sensu novo) is given in Table 2. The family-group names follow [32, 33]. The concepts sensu novo for the tribes Deltochilini and Dichotomiini correspond to their concepts sensu stricto in [1]. The redifined tribes emerged monophyletic in all the analyses presented here and are also suppotreted by previous phylgoentic work [1,11-13, 19-22]; their support values are provided in Table 3.
In this study, unlike [32, 33], we consider Dichotomiini and Ateuchini to be different tribes (see "Tribe Dichotomiini sensu novo and the case of Ateuchini" section). Our new concept for Dichotomiini introduces changes in the composition of genera in Ateuchini. The list of putative Ateuchini genera is given in Additional file 23: Table S9. The genera, which are, excluded form the revised tribes and treated as incertae sedis are also listed in the Additional file 23: Table S9.

\section{Tribal diagnoses}

The synapomorphies and diagnostic characters were identified based on the results from the recent global morphological phylogeny [1] and are provided in Figs. 4, 5 and Table 1. That morphological study covers all major dung beetle lineages and thereby is the best source for analyzing evolution of morphological characters in this group. Herein, the term synapomorphy refers exclusively to unambiguous synapomorphies which were identified in morphological phylogeny [1] by parsimony mapping of the morphological characters onto the selected most parsimonious tree (Fig. 6 in [1]). These synapomorphies can be classified into (i) non-homoplasious that uniquely identify clade and (ii) homoplasious that in addition to the clade of interest can identify some other clade.

Diagnostic characters (e.g., in Coprini sensu novo and Sisyphini sensu novo) were elucidated using the character matrix of [1] by finding a unique combination of characters providing unequivocal diagnosis for the new concepts. Since Coprini sensu novo is not strictly monophyletic in [1] (see "Tribe Coprini sensu novo" chapter for discussion), its synapomorphies could not be assessed. Sisyphini sensu novo is characterized by both synapomorphies and one diagnostic character. We should note that diagnostic character might also be ambiguous synapomorphies.

Because the morphological phylogeny [1] includes only $37 \%$ of the global scarabaeine generic diversity, we manually investigated the presence of the potential diagnostic characters and putative synapomorphies in $~ 90 \%$ of all Scarabaeinae genera hitherto placed in Deltochilini, Dichotomiini and Coprini (see also Table 2).

\section{Tribe Coprini sensu novo}

Coprini Leach 1815: 96 (Coprides)

Type genus: Copris Geoffroy, 1762

\section{Systematic note}

Part of the genera of Coprini sensu novo (Copris and Litocopris) are monophyletic in the present molecular phylogeny. The global morphological phylogeny [1] reveals a polytomy of Copris with Pseudopedaria + Micorcopris (clade L4, Fig. 6 in [1]). The lack of resolution in 


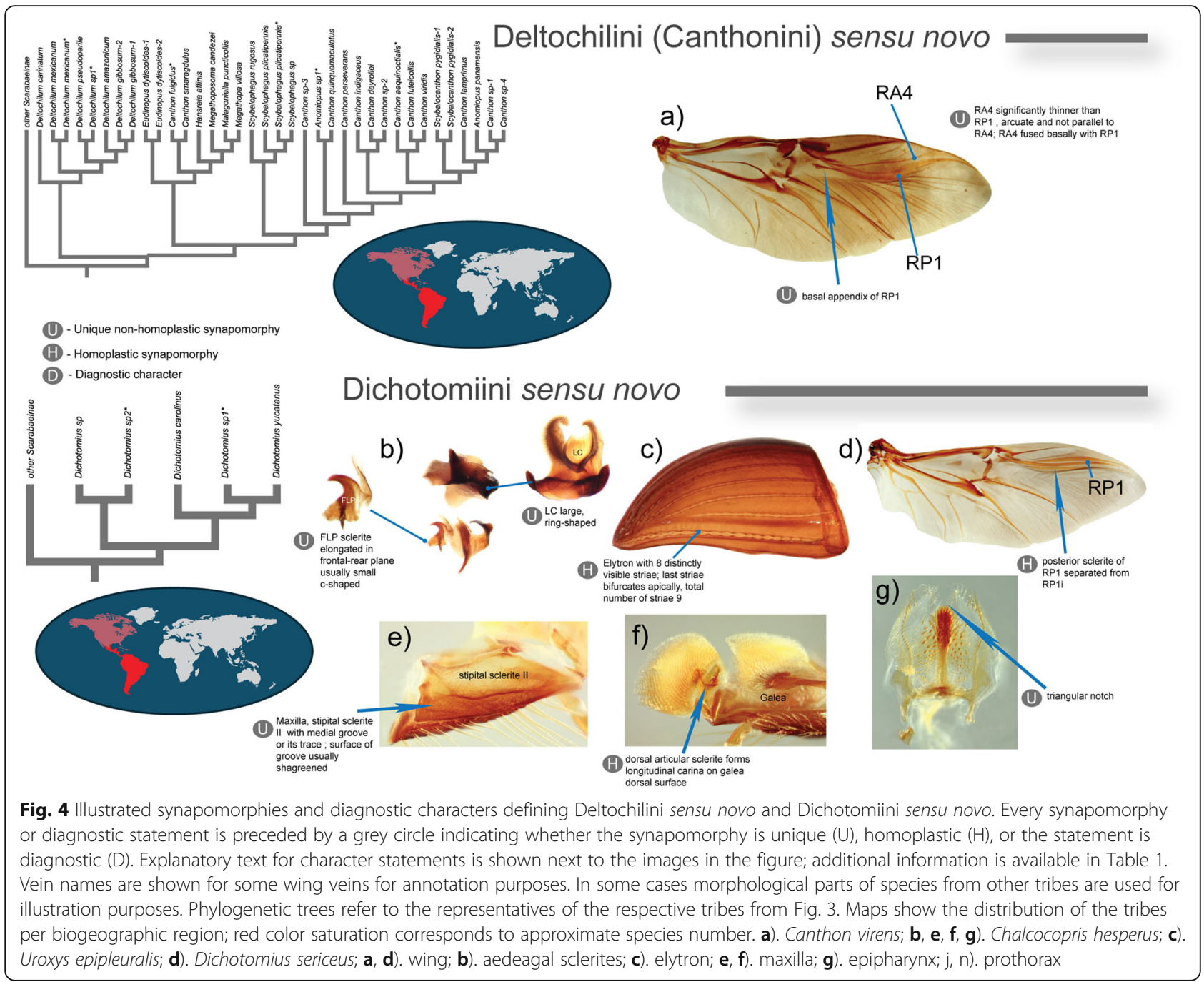

Coprini sensu novo in morphology is the probable result of incomplete species sample from this tribe. It is noteworthy that genus Microcopris is considered by some authors [67] as a subgenus of Copris pointing out to their close relationship. In spite of lack of resolution, the present molecular results generally corroborate the morphological finding providing further evidence for the monophyly of Coprini sensu novo. However, more data are desirable to improve the support for this group.

In the present study Coprini sensu novo is well supported by ML and BI (Table 3); previous studies also suggest a separate monophyletic position for the members of Coprini sensu novo [1, 11, 22]. Coprini sensu novo comprises five genera (Table 2), all of which were members of the traditionally defined Coprini. We confidently place Catharsius, Metacatharsius, Coptodactyla, previously considered Coprini, outside Coprini sensu novo as neither molecules nor morphology support this placement. We transfer a few other Coprini genera Thyregis, Synapsis, Copridaspidus not included in present analyses to incertae sedis based on another morphological phylogeny [15] suggesting their sister relationships to the non-Coprini sensu novo genera Coptodactyla, Heliocopris and Catharsius correspondingly. All genera transferred to the incertae sedis category are listed in Additional file 23: Table S9.

\section{Diagnosis and synapomorphies}

The lack of resolution in morphology makes identification of synapomorphies difficult for this tribe; therefore, here we provide only diagnostic characters aiding efficient identification of Coprini sensu novo. The tribe can be unequivocally differentiated by combination of two character states (Fig. 4 and Table 1): (i) apical area of wing bearing sclerite located posteriorly of $\mathrm{RP}_{1}$ and (ii) absent pre-epipleural (1st) elytral carina. In addition, species of Coprini sensu novo also share the following combination of character states: (i) SRP simple not ringshaped, (ii) elytron with 10 distinctly visible striae and (iii) anterior ridge of hypomera stretches toward lateral 


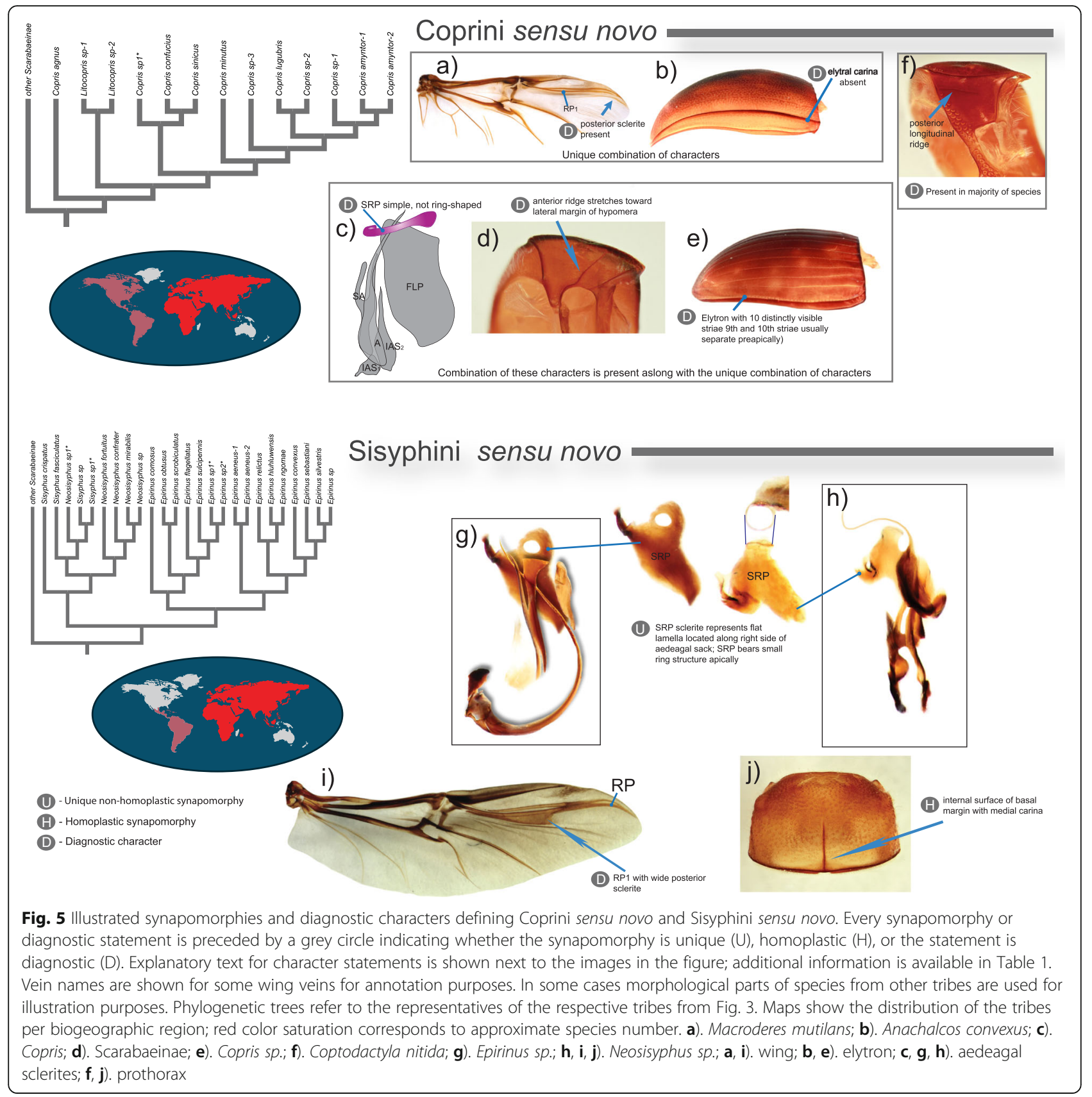

margin of hypomera. The majority of genera, (except. Microcopris, for example), have hypomera with posterior longitudinal ridge; however, this character is present in other non-Coprini sensu novo genera as well (see character matrix in [1]).

\section{Distribution}

All five genera of Coprini sensu novo genera are primarily distributed in the Afrotropical and Oriental Regions. Some species of the type genus Copris are also found in North and Central America.
Tribe Deltochilini (Canthonini) sensu novo

Deltochilini Lacordaire 1856: 78 (Deltochilides)

Canthonini van Lansberge 1874: 184 (Canthonides, type genus: Canthon Hoffmannsegg, 1817)

Scatonomini Lacordaire 1856: 87 (Scatonomides, type genus: Scatonomus Erichson, 1835)

Type genus: Deltochilum Eschscholtz, 1822

\section{Systematic note}

The traditional concept of the tribe Deltochilini (Canthonini) comprising 100+ genera was recovered 
Table 1 Synapomorphies and diagnostic characters defining new tribal concepts

Tribe Deltochilini (Canthonini) sensu novo:

$U$ 101. Wing, $R P_{1}$ posterior sclerite represents small basal appendix of $R P$ Note: In Anisocanthon basal appendix of $\mathrm{RP}_{1}$ is reduced and poorly visible. In Pseudocanthon appendix of $\mathrm{RP}_{1}$ is separated from $\mathrm{RP}_{1}$.

$U$ 103. Wing, $R A_{4}$ significantly thinner than $R P_{1}$, arcuate and not parallel to $R A_{4} ; R A_{4}$ fused basally with $R P_{1}$.

Tribe Dichotomiini sensu novo:

H 13. Parameres, membrane on lower side strongly sclerotized with two notches basally.

Note: Investigation of additional material revealed that this character is absent in some Dichotomiini sensu novo which suggests a change of its status to at least a homoplastic synapomorphy and at the same time decreases the power of its diagnosability; therefore this character is not illustrated here.

U 58. FLP sclerite elongated in frontal-rear plane usually small c-shaped. Note: For readability purpose, the original character statement [1] was reworded.

$U$ 62. LC large, ring-shaped in horizontal plane.

H 66. Elytron with 8 distinctly visible striae. Note: The number of visible striae is 8 , the total number of striae is 9 as the last stria indistinctly bifurcates apically.

$H$ 105. Wing, posterior sclerite of $R P_{1}$ separated from $R P_{1}$

U 123. Maxilla, stipital sclerite II with medial groove or its trace; surface of groove usually shagreened.

Note: For readability purpose, the original character statement [1] was reworded.

H 124. Galea, dorsal articular sclerite forms longitudinal carina on galea dorsal surface.

Note: In [1] this character represents a unique synapomorphy; however, it is absent in Isocopris (that was not included in [1]) that suggests a change of its status to at least a homoplastic synapomorphy.

U 139. Epipharynx with triangular deep notch anteriorly.

Tribe Sisyphini sensu novo:

U 50. SRP sclerite represents flat lamella located along right side of aedeagal sack; SRP bears small ring structure apically

U 86. Elytron, last stria $\left(9^{\text {th }}\right.$ or $\left.8^{\text {th }}\right)$ visible at least preapically. Note: For readability purpose, the original character statement [1] was reworded. We consider $8^{\text {th }}$ stria in Neosisyphus and $9^{\text {th }}$ in Epirinus to be homologous according to the criterion of position. This character reflects the degree of development of this stria. Since, the original statement, formulated for the needs of phylogenetic analysis, does not meet the needs of diagnosability, this character is not illustrated here but can be found in [1].

H 162. Pronotum, internal surface of basal margin with medial carina. Note: The degree of expression of this character varies within Sisyphini sensu novo.

D 102. Wing, $R P_{1}$ with wide posterior sclerite. Note: Although this character does not represent an unambiguous synapomorphy in [1], it can be efficiently used for diagnostic purposes. In addition to Sisyphini sensu novo this character is also present in Onthophagini and Oniticellini.

Tribe Coprini sensu novo:

$D$ 113. Wing, apical area bears sclerite located posteriorly of $R P_{1}$.

D 73. $1^{\text {st }}$ elytral carina absent.
Table 1 Synapomorphies and diagnostic characters defining new tribal concepts (Continued)

D 48. SRP simple not ring-shaped.

D 68. Elytron with 10 distinctly visible striae $\left(9^{\text {th }}\right.$ and $10^{\text {th }}$ striae usually separate preapically).

Note: For readability purpose, the original character statement [1] was reworded.

D 157. Hypomera, anterior ridge stretches toward lateral margin of hypomera.

D 161. Hypomera, posterior longitudinal ridge present.

This table lists synapomorphies and diagnostic characters defining the new tribal concepts. Number preceding character statement refers to the character number in [1]; capital letter indicates unique synapomorphy (U), homoplastic synapomorphy $(\mathrm{H})$ and diagnostic character $(\mathrm{D})$. The listed characters are illustrated in Figs. 4, 5 (except characters 13 and 86, see notes), additional information is provided in "Changes in classification" section

highly polyphyletic by our results and previous studies $[1,10,11,22]$. Deltochilini as traditionally defined form numerous monophyletic groups spread across the phylogenetic tree of Scarabaeinae. Both molecular results presented here (Table 3 for ML bootstrap and BI support) and morphological results [1] recover the monophyletic group of true Deltochilini (i.e. Deltochilini sensu novo) comprising the type genus of the tribe and allies, all of which exclusively occur in the New World. Morphological phylogeny recovered 11 , while present molecular phylogeny recovered 10 genera in the clade Deltochilini sensu novo, 8 of those genera were shared between the two phylogenies (Table 2).

\section{Diagnosis and synapomorphies}

The morphological phylogeny suggests two unique and easily identifiable synapomorphies in wing venation (Fig. 4 and Table 1) characterizing the diagnosis of this new tribal concept. Investigation of morphology in genera traditionally assigned to Deltochilini and Dichotomiini allowed us to identify additional 9 genera that share the same synapomorphies with Deltochilini sensu novo. Based on this finding we assign these genera to the Deltochilini sensu novo. Beside those unique synapomorphies the general morphology of those 9 genera is similar to that of the genera included in our phylogenetic analyses. As a result, the new definition of Deltochilini limits its traditional concept by leaving only 22 genera out of $100+$ within that tribe (Table 2).

\section{Distribution}

The majority of genera are distributed in the Neotropics, while some also occur in the Nearctic Region. Numerous other genera traditionally placed in Deltochilini from New World, all from Afrotropics, Oriental and Australasian Regions do not belong to Deltochilini sensu novo nor to any other known tribe given the results of aforementioned phylogenies; herein we treat them as incertae sedis (Additional file 23: Table S9). 
Table 2 New tribal concepts and their genera

\begin{tabular}{llll}
\hline \multicolumn{2}{l}{ Tribe/Genera } & Inv. & Biogeographic Region \\
\hline \multicolumn{2}{l}{ Tribe Sisyphini sensu novo } & & \\
1 & Epirinus Reiche, 1841 & $\mathrm{M}, \mathrm{P}$ & Afrotropical \\
2 & Neosisyphus Muller, 1942 & $\mathrm{M}, \mathrm{P}$ & Afrotropical, Oriental \\
3 & Nesosisyphus Vinson, 1946 & $\mathrm{L}$ & Mauritius \\
4 & Sisyphus Latreille, 1807 & $\mathrm{P}$ & Afrotropical, Oriental, Palaearctic, Neotropical
\end{tabular}

Tribe Dichotomiini sensu novo

$\begin{array}{llll}1 & \text { Chalcocopris Burmeister, 1846 } & \text { M } & \text { Neotropical } \\ 2 & \text { Dichotomius Hope, } 1838 & \text { M, P } & \text { Neotropical, Nearctic } \\ 3 & \text { Holocephalus Hope, 1838 } & \text { S } & \text { Neotropical } \\ 4 & \text { Isocopris Pereira \& Martinez, 1960 } & \text { S } & \text { Neotropical }\end{array}$

Tribe Coprini sensu novo

\begin{tabular}{|c|c|c|c|}
\hline 1 & Copris Muller, 1764 & $M, P$ & Afrotropical, Oriental, Palaearctic, Nearctic, Neotropical \\
\hline 2 & Litocopris Waterhouse, 1891 & $P$ & Afrotropical \\
\hline 3 & Microcopris Balthasar 1958 & M & Oriental \\
\hline 4 & Pseudocopris Ferreira, 1960 & L & Afrotropical \\
\hline 5 & Pseudopedaria Felsche, 1904 & M & Afrotropical \\
\hline \multicolumn{4}{|c|}{ Tribe Deltochilini (Canthonini) sensu novo } \\
\hline 1 & Anisocanthon Martinez \& Perreira, 1956 & S & Neotropical \\
\hline 2 & Anomiopus Westwood, 1842 & $M, P$ & Neotropical \\
\hline 3 & Canthon Hoffmansegg, 1817 & $M, P$ & Neotropical, Nearctic \\
\hline 4 & Canthonidia Paulian, 1939 & S & Neotropical \\
\hline 5 & Canthotrypes Paulian, 1939 & $\mathrm{~S}$ & Neotropical \\
\hline 6 & Deltepilissus Pereira, 1949 & S & Neotropical \\
\hline 7 & Deltochilum Eschscholtz, 1822 & $M, P$ & Neotropical, Nearctic \\
\hline 8 & Eudinopus Burmeister, 1840 & $P$ & Neotropical \\
\hline 9 & Hansreia Halffter \& Martinez, 1977 & $M, P$ & Neotropical \\
\hline 10 & Holocanthon Martinez \& Pereira, 1956 & S & Neotropical \\
\hline 11 & Malagoniella Martinez, 1961 & $M, P$ & Neotropical \\
\hline 12 & Megathopa Eschscholtz, 1822 & $P$ & Neotropical \\
\hline 13 & Megathoposoma Balthasar, 1939 & $M, P$ & Neotropical \\
\hline 14 & Melanocanthon Halffter, 1958 & S & Nearctic \\
\hline 15 & Pseudocanthon Bates, 1887 & S & Neotropical, Nearctic \\
\hline 16 & Scatonomus Erichson, 1835 & M & Neotropical \\
\hline 17 & Scybalocanthon Martinez, 1948 & $M, P$ & Neotropical \\
\hline 18 & Scybalophagus Martinez, 1953 & $M, P$ & Neotropical \\
\hline 19 & Sylvicanthon Halffter \& Marttinez, 1977 & M & Neotropical \\
\hline 20 & Tetraechma Blanchard, 1843 & M & Neotropical \\
\hline 21 & Vulcanocanthon Pereira \& Martinez, 1960 & S & Neotropical \\
\hline 22 & Xenocanthon Martinez, 1952 & $\mathrm{~S}$ & Neotropical \\
\hline
\end{tabular}

List of genera assigned to the redefined tribes based on their new concepts. Column "Inv." (investigation source) specifies evidence based on which genus was attributed to the tribe. Abbreviations are as follows: (M) morphological phylogeny [1], (P) present phylogeny, (S) synapomorphies or diagnostic characters checked (material examined per genus is given in Additional file 24: Table S6), (L) synapomorphies or diagnostic characters were not investigated and genus was attributed based on description and overall similarity to the type genus of tribe 
Table 3 The support for the new tribal concepts in Scarabaeinae

\begin{tabular}{llllll}
\hline TribelDataset & ALL & G20 & DT3 & BI (G20) & Citations \\
\hline Sisyphini sensu novo & 81 & 77 & 58 & 1 & {$[1,66]$} \\
Dichotomiini sensu novo & 83 & 78 & 51 & 1 & {$[1,10,11,19,22]$} \\
Coprini sensu novo & 100 & 100 & 100 & 1 & {$[1,11,22]$} \\
Deltochilini sensu novo & 43 & 49 & 44 & 1 & {$[1,10,11,19,22]$}
\end{tabular}

Columns "ALL", "G20" and "DT3" show bootstrap support for the new tribal concepts in ML analyses. Column "BI" shows Bayesian posterior probabilities for the analysis with G20 dataset. Column "Citations" lists publications which suggest similar tribal relationships

Tribe Dichotomiini sensu novo and the case of Ateuchini Pinotini Kolbe 1905: 548 (Pinotinae)

Dichotomiini Pereira 1954:55

Dichotomides Halffter 1961:228

Dichotomiini Halffter and Matthews 1966: 256

Type genus: Dichotomius Hope, 1838 (Pinotus Erichson, 1847 is a junior synonym of Dichotomius Hope, 1838)

\section{Systematic note}

The name Dichotomiini has been hitherto considered unavailable as a family-group name due to the lack of description or validation [32] but nevertheless was widely used in Scarabaeinae. Thanks to our colleague (F. Vaz-de-Mello, CEMT) who gave a hint to previously overlooked publication [68], the name Dichotomiini has to be deemed available. According to the International Code of Zoological Nomenclature Article 13.2.1 [69] "a family-group name first published after 1930 and before $1961 \ldots$ is available from its original publication only if it was used as valid before 2000 ...". The name Dichotomiini after its original publication in 1954 [68] was subsequently used before 2000 (e.g. [70]) which given the aforementioned Article confirms its availability.

Tribe Dichotomiini has been considered a junior synonym of Ateuchini [32] as the genus Dichotomius was deemed to be closely related to Ateuchus (the type genus for the tribe Ateuchini Laporte, 1840). Morphological phylogeny recovers that Ateuchus and allies (clade F1, Fig. 6 in [1]) are remotely related to Dichotomius lineage. Present molecular result recovers polyphyly of Ateuchini and suggests sister group relationship between Dichotomius and Ateuchus + Scatimus, while other representatives of Ateuchini subtribe Scatimina emerge as more remotely related. Although, molecular results support the monophyly of Dichotomius + Ateuchus, morphological analyses unequivocally point to their significant morphological divergence. In order to fulfill abovementioned classification principles, it is therefore convenient to separate Dichotomius + allies and Ateuchus + allies into two tribes. The main objective for following the splitting principle is to create the diagnosable groups. Thus, we split the tribe Ateuchini into two tribes Ateuchini and Dichotomiini sensu novo. In the present study
Dichotomiini sensu novo is well supported by ML and BI (Table 3). The name Ateuchini has now to be applied only to the members of the genus Ateuchus and its close relatives (sensu [61]). The tentative list comprising 20 Ateuchini genera is given in Additional file 23: Table S9; however, the exact composition and diagnosis of this tribe requires additional investigation. The genera transferred from the traditional concept of Dichotomiini to incertae sedis category are also listed in Additional file 23: Table S9.

\section{Diagnosis and synapomorphies}

The monophyly of Dichotomiini sensu novo is well supported by molecules [11, 19, 22] as well as morphology $[1,10]$. Based on recent morphological analyses [1] Dichotomiini sensu novo is defined by 4 unique and 4 homoplasious synapomorphies (Fig. 4, Table 1) which unequivocally diagnose this tribe.

\section{Distribution}

Dichotomiini sensu novo comprises four genera (Table 2) widespread in the Neotropics, of which Dichotomius is distributed in both Nearctic and Neotropical Regions.

\section{Tribe Sisyphini sensu novo}

Sisyphini Mulsant 1842: 41 (Sisyphaires)

Type genus: Sisyphus Latreille, 1807

\section{Systematic note}

Genus Epirinus is found to be sister to the traditional Sisyphini genera Sisyphus and Neosisyphus. Present and previous [66] molecular as well as morphological [1] results strongly support this relationship, which suggests the transfer of Epirinus to Sisyphini. In present study Sisyphini sensu novo is well supported by ML and BI (Additional file 4: Table S3).

\section{Diagnosis and synapomorphies}

The diagnosis of expanded Sisyphini sensu novo is defined by two unique and one homoplasious synapomorphies (Fig. 4, Table 1).

\section{Distribution}

Sisyphini sensu novo comprises four genera, two of which Sisyphus and Neosisyphus primarily occur in the Afrotropical and Oriental Regions, some species of Sisyphus are also distributed in the Palearctic and the Neotropics. The distribution of the genus Neosisyphus is restricted to Mauritius Island, while Epirinus occurs in southern Africa. 


\section{Conclusions}

The present molecular phylogeny advances our knowledge on dung beetle relationships. We used these results in conjunction with the recent morphological phylogeny and evidences from molecular phylogenies that have been accumulated over the last decades to revise the concepts of three of the subfamily's most problematic tribes (Deltochilini, Dichotomiini and Coprini). Although the result of the new classification proposed here leaves many dung beetle genera unclassified (incertae sedis), it creates a systematically based classification for the existing tribes and provides a clear direction for future work with these genera. At the same time deep relationships within the subfamily remain poorly supported pointing to the need of acquisition of additional data to resolve them. These issues have to be addressed by future studies aiming at integration of molecular, morphological and fossil data.

We propose that use of modern statistical methods for model adequacy evaluation has a potential to improve phylogenetic inference by detecting cases where substitution models do not perform well. Presently, data selection using this approach cannot be fully performed on big datasets due to computational constraints. The development of new software packages is needed to overcome this problem. At the same time it is noteworthy that inclusion of data where models do not adequately depict substitution process according to our analysis, did not substantially affect the final phylogenetic analyses. Likely the presence of strong signal in our dataset from large portions where the application of substitution models is plausible has compensated for the potential biases caused by the inclusion of partitions that were rejected in the adequacy assessments.

\section{Additional files}

\section{Additional file 1: Table S1. Accession numbers and vouchers} information. (XLSX 64 kb)

Additional file 2: Table S2. List of genera with author citations. (XLSX $12 \mathrm{~kb}$ )

Additional file 3: Matrix S1. Data matrix used in the phylogenetic analyses. (NEX $3130 \mathrm{~kb}$ )

Additional file 4: Table S3. Primers used in the study. (DOCX 17 kb) Additional file 5: Table S4. Partitions and their models used in the analyses. (DOCX $16 \mathrm{~kb}$ )

Additional file 6: Table S5. Data blocks and their $p$-values assessed using Bayesian posterior prediction in PuMA. (DOCX $17 \mathrm{~kb}$ )

Additional file 7: Statistics for MrBayes Runs. (ZIP 395 kb)

Additional file 8: Tree S12. Scarabaeinae ML tree of dataset ALL using at least 4 genes (including 18 s, 28sd2, 28sd3, CAD, 16 s, Tp1). (TREE 17 kb)

Additional file 9: Tree S13. Scarabaeinae ML tree of dataset DT3 using at least 5 genes (including $18 \mathrm{~s}, 28 \mathrm{sd} 2,28 \mathrm{sd} 3, \mathrm{CAD}, 16 \mathrm{~s}, \mathrm{Tp} 1, \mathrm{COI}, \mathrm{CAD}$ ). (TREE 5 kb)
Additional file 10: Tree S1. Scarabaeinae ML tree of dataset ALL. (TREE $37 \mathrm{~kb}$ )

Additional file 11: Tree S2. Scarabaeinae ML tree of dataset G20 (TREE $37 \mathrm{~kb}$ )

Additional file 12: Tree S3. Scarabaeinae ML tree of dataset DT3. (TREE $37 \mathrm{~kb}$ )

Additional file 13: Table S7. Robinson-Fold distance and proportion of shared clades between ML analyses using datasets ALL, G20 and DT3 as well as Bl with MrBayes using G20 dataset. (XLS 27 kb)

Additional file 14: Tree S4. MrBayes 50\% majority consensus tree with support statistics. (TRE $270 \mathrm{~kb}$ )

Additional file 15: Tree S5. MrBayes 50\% majority consensus tree with collapsed ambiguous branches (see Additional file 6 for details). (TRE $21 \mathrm{~kb}$ )

Additional file 16: Tree S6. POY Tree, estimated using parameter scheme 111 (see Methods section). (TRE $12 \mathrm{~kb}$ )

Additional file 17: Tree S7. POY Tree, estimated using parameter scheme 121 (see Methods section). (TRE $12 \mathrm{~kb}$ )

Additional file 18: Tree S8. POY Tree, estimated using parameter scheme 211 (see Methods section). (TRE $12 \mathrm{~kb}$ )

Additional file 19: Tree S9. POY Tree, estimated using parameter scheme 221 (see Methods section). (TRE $12 \mathrm{~kb}$ )

Additional file 20: Tree S10. POY Tree, estimated using parameter scheme 3211 (see Methods section). (TRE $12 \mathrm{~kb}$ )

Additional file 21: Tree S11. POY Tree, estimated using parameter scheme 3221 (see Methods section). (TRE $12 \mathrm{~kb}$ )

Additional file 22: Table S8. Bootstrap support in $M L$ and posterior probabilities in $\mathrm{BI}$ analyses for the major inferred Scarabaeinae lineages. (XLSX $38 \mathrm{~kb}$ )

Additional file 23: Table S9. The list of Scarabaeinae genera attributed to the tribe Ateuchini and category incertae sedis. (XLS $40 \mathrm{~kb}$ )

Additional file 24: Table S6. Species used to check synapomorphies for the new tribal concepts. (DOCX $16 \mathrm{~kb}$ )

\section{Acknowledgements}

This paper would not have been possible without the Scarab Research Group at the University of Pretoria, South Africa whose help we greatly appreciate. We are thankful to the leader and all members of the Scarab Research Group namely, C. Scholtz (the leader), C. Sole, W. Strumpher, C. du Toit, A. Davis, Ch. Deschodt who provided the list of Scarabaeinae genera as well as many specimens for molecular work and helped in organizing fruitful field trips in South Africa. We are indebted and grateful to many of our colleagues who contributed to this study by kindly providing crucial specimens, assisting in identification of species and organization of fieldtrips: F. Vaz-de-Mello, A. Solodovnikov, V. Grebennikov, A. Newton, M. Thayer, J. Boone, A. Smith, V. Gusarov, J. Pedersen, J. Mondaca, O. Montreuil, A. Schomann, I. Hanski, K.P. Puliafico, N. Gunter, C. Medina, A. Gonzales, J. Noriega, S. Forgie, R. Leschen, D. Mann, R. Ruta, B. Kohlmann, A. Solis, F. Genier, A. Brunke, S. Selvantharan, C. Lemann, T. Weir, B. Gill. We are grateful to J. Nylander for his suggestions on MrBayes usage and to F. Genier for providing habitus pictures of dung beetles. We would like to thank K.P. Puliafico for the linguistic check of the text as well as Nicole Gunter and two anonymous reviewers for their comments that led to the improvement of the manuscript. The computations were performed on the Abel Cluster, owned by the University of Oslo and the Norwegian metacenter for High Performance Computing (NOTUR), and operated by the Department for Research Computing at USIT, the University of Oslo IT-department (http://www.hpc.uio.no/).

\section{Funding}

Visits of ST to the MNHN in Paris received support from the SYNTHESYS grant (http://www.synthesys.info). The funders had no role in study design, data collection and analysis, decision to publish, or preparation of the manuscript.

Availability of data and materials

The datasets supporting the conclusions of this article are included within its Additional files. 


\section{Authors' contributions}

ST designed research; ST assembled material and performed the lab work; ST and DD performed analyses; ST and DD wrote the paper. Both authors read and approved the final manuscript.

\section{Competing interests}

The authors declare that they have no competing interests.

\section{Consent for publication}

Not applicable.

\section{Ethics approvals and consent to participate}

Not applicable.

Received: 23 September 2016 Accepted: 28 October 2016 Published online: 29 November 2016

\section{References}

1. Tarasov S, Génier F: Innovative Bayesian and Parsimony Phylogeny of Dung Beetles (Coleoptera, Scarabaeidae, Scarabaeinae) Enhanced by Ontology-Based Partitioning of Morphological Characters. PLoS One 2015, 10(3):doi:10.1371/journal.pone.0116671.

2. Nichols E, Spector S, Louzada J, Larsen T, Amezquita S, Favila ME. Ecological functions and ecosystem services provided by Scarabaeinae dung beetles. Biol Conserv. 2008;141(6):1461-74.

3. Nichols ES, Gardner TA. Dung beetles as a candidate study taxon in applied biodiversity conservation research. In: Simmons LW, Ridsdill-Smith TJ, editors. Ecology and evolution of dung beetles. Chichester: John Wiley \& Sons, Ltd.; 2011. p. 267-91.

4. Baillie JE, Collen B, Amin R, Akcakaya HR, Butchart SH, Brummitt N, Meagher TR, Ram M, Hilton-Taylor C, Mace GM. Toward monitoring global biodiversity. Conserv Lett. 2008;1(1):18-26.

5. Spector S. Scarabaeine dung beetles (Coleoptera: Scarabaeidae: Scarabaeinae): an invertebrate focal taxon for biodiversity research and conservation. Coleopterists Society Monographs Patricia Vaurie Series. 2006;5:71-83.

6. Moczek A. Evolution and development: onthophagus beetles and the evolutionary developmental genetics of innovation, allometry and plasticity. Oxford: Dung beetle ecology and evolution Wiley-Blackwell; 2011. p. 126-51.

7. Scholtz CH, Davis ALV, Kryger U. Evolutionary biology and conservation of dung beetles. Bulgaria: Pensoft Sofia; 2009

8. Philips TK, Pretorius E, Scholtz CH. A phylogenetic analysis of dung beetles (Scarabaeinae: Scarabaeidae): unrolling an evolutionary history. Invertebr Syst. 2004;18(1):53-88.

9. Pretorius R, Philips K, Scholtz C. Geometric morphometrics, the metendosternite and its use in phylogenetics of the Scarabaeinae (Coleoptera). Elytron (Barcelona). 2000;14:125-48.

10. Vaz-de-Mello FZ. Revision taxonomica e analysis phylogenetico de la tribu Ateuchini. Xalapa, Veracruz, Mexico: Instituto de Ecologia A.C.; 2007.

11. Monaghan MT, Inward DJG, Hunt T, Vogler AP. A molecular phylogenetic analysis of the Scarabaeinae (dung beetles). Mol Phylogenet Evol. 2007; 45(2):674-92.

12. Sole $\mathrm{CL}$, Scholtz $\mathrm{CH}$. Did dung beetles arise in Africa? A phylogenetic hypothesis based on five gene regions. Mol Phylogenet Evol. 2010; 56(2):631-41.

13. Wirta H, Viljanen $H$, Orsini L, Montreuil O, Hanski I. Three parallel radiations of Canthonini dung beetles in Madagascar. Mol Phylogenet Evol. 2010;57(2):710-27.

14. Zunino M. Essai preliminaire sur l'evolution des armures genitales des Scarabaeinae, par rapport a la taxonomie du groupe et a l'evolution du comportement de nidification (Col. Scarabaeidae). Bulletin de la Societe entomologique de France. 1983:88(7-8):531-42.

15. Montreuil O. Phylogenetic analysis and paraphyly of Coprini and Dichotomiini (Coleoptera: Scarabaeidae). Biogeographic scenario. Annales de la Société Entomologique de France. 1998;34(2):135-48.

16. Vaz-de-Mello FZ. Revision and phylogeny of the dung beetle genus Zonocopris Arrow 1932 (Coleoptera: Scarabaeidae: Scarabaeinae), a phoretic of land snails. Annales de la Société Entomologique de France. 2007:43(2):231-9.
17. Bai M, McCullough E, Song K-Q, Liu W-G, Yang X-K. Evolutionary constraints in hind wing shape in Chinese dung beetles (Coleoptera: Scarabaeinae). PLoS One. 2011;6(6):e21600.

18. Villalba S, Lobo JM, Martin-Piera F, Zardoya R. Phylogenetic relationships of Iberian dung beetles (Coleoptera: Scarabaeinae): insights on the evolution of nesting behavior. J Mol Evol. 2002;55(1):116-26.

19. Ocampo FC, Hawks DC. Molecular phylogenetics and evolution of the food relocation behaviour of the dung beetle tribe Eucraniini (Coleoptera, Scarabaeidae, Scarabaeinae). Invertebr Syst. 2006;20(5):557-70.

20. Wirta $H$, Orsini L, Hanski I. An old adaptive radiation of forest dung beetles in Madagascar. Mol Phylogenet Evol. 2008:47(3):1076-89.

21. Mlambo S, Sole CL, Scholtz CH. Affinities of the Canthonini dung beetles of the Eastern Arc Mountains. Org Divers Evol. 2014;14(1):115-20.

22. Gunter NL, Weir TA, Slipinksi A, Bocak L, Cameron SL. If Dung Beetles (Scarabaeidae: Scarabaeinae) Arose in Association with Dinosaurs, Did They Also Suffer a Mass Co-Extinction at the K-Pg Boundary? PLoS One. 2016; 11(5):e0153570.

23. Regier JC, Zwick A, Cummings MP, Kawahara AY, Cho S, Weller S, Roe A, Baixeras J, Brown JW, Parr C. Toward reconstructing the evolution of advanced moths and butterflies (Lepidoptera: Ditrysia): an initial molecular study. BMC Evol Biol. 2009:9(1):280.

24. Lemmon AR, Moriarty EC. The importance of proper model assumption in Bayesian phylogenetics. Syst Biol. 2004;53(2):265-77.

25. Brown JM. Detection of implausible phylogenetic inferences using posterior predictive assessment of model fit. Syst Biol. 2014;63(3):334-48.

26. Brown JM. Predictive approaches to assessing the fit of evolutionary models. Syst Biol. 2014;63(3):289-92.

27. Philips TK. The evolutionary history and diversification of dung beetles. In: Simmons LW, Ridsdill-Smith TJ, editors. Ecology and evolution of dung beetles. Oxford: Blackwell Publishing Ltd. 2011. pp. 21-46.

28. Smith ABT, Hawks DC, Heraty JM. An overview of the classification and evolution of the major scarab beetle clades (Coleoptera: Scarabaeoidea) based on preliminary molecular analyses. Coleopterists Society Monographs Patricia Vaurie Series, 2006:5:35-46.

29. Lawrence JF, Slipinski A, Seago AE, Thayer MK, Newton AF, Marvaldi AE. Phylogeny of the Coleoptera Based on Morphological Characters of Adults and Larvae. Ann Zool. 2011;61(1):1-217.

30. Browne J, Scholtz C. Evolution of the scarab hindwing articulation and wing base: a contribution toward the phylogeny of the Scarabaeidae (Scarabaeoidea: Coleoptera). Syst Entomol. 1998;23:307-26.

31. Ahrens D, Schwarzer J, Vogler AP. The evolution of scarab beetles tracks the sequential rise of angiosperms and mammals. Proc R Soc B Biol Sci. 2014; 281(1791):20141470.

32. Smith $A B$. A review of the family-group names for the superfamily Scarabaeoidea (Coleoptera) with corrections to nomenclature and a current classification. Coleopt Bull. 2006;60(sp5):144-204.

33. Bouchard $P$, Bousquet $Y$, Davies A, Alonso-Zarazaga M, Lawrence J, Lyal C, Newton A, Reid C, Schmitt M, Slipinski A, et al. Family-Group Names In Coleoptera (Insecta). Zookeys. 2011:88:1-972.

34. Miraldo A, Hanski IA. Competitive release leads to range expansion and rampan speciation in malagasy dung beetles. Systematic Biol. 2014;63(4):480-92.

35. Osswald J, Bachmann L, Gusarov VI. Molecular phylogeny of the beetle tribe Oxypodini (Coleoptera: Staphylinidae: Aleocharinae). Syst Entomol. 2013; 38(3):507-22.

36. Wild AL, Maddison DR. Evaluating nuclear protein-coding genes for phylogenetic utility in beetles. Mol Phylogenet Evol. 2008;48(3):877-91.

37. Kearse M, Moir R, Wilson A, Stones-Havas S, Cheung M, Sturrock S, Buxton S, Cooper A, Markowitz S, Duran C. Geneious Basic: an integrated and extendable desktop software platform for the organization and analysis of sequence data. Bioinformatics. 2012;28(12):1647-9.

38. Katoh K, Standley DM. MAFFT multiple sequence alignment software version 7 : improvements in performance and usability. Mol Biol Evol. 2013;30(4):772-80.

39. Bernhart SH, Hofacker IL, Will S, Gruber AR, Stadler PF. RNAalifold: improved consensus structure prediction for RNA alignments. BMC Bioinformatics. 2008;9(1):474

40. Smith C, Heyne S, Richter AS, Will S, Backofen R. Freiburg RNA Tools: a web server integrating INTARNA, EXPARNA and LOCARNA. Nucleic Acids Res. 2010;38 suppl 2:W373-7.

41. Lin C-P, Danforth BN. How do insect nuclear and mitochondrial gene substitution patterns differ? Insights from Bayesian analyses of combined datasets. Mol Phylogenet Evol. 2004;30(3):686-702. 
42. Swofford DL, Olsen GJ, Waddell PJ, Hillis DM. Phylogenetic inference. 1996.

43. Jones P, Binns D, Chang H-Y, Fraser M, Li W, McAnulla C, McWilliam H, Maslen J, Mitchell A, Nuka G. InterProScan 5: genome-scale protein function classification. Bioinformatics. 2014;30(9):1236-40.

44. Mitchell A, Chang H-Y, Daugherty L, Fraser M, Hunter S, Lopez R, McAnulla C, McMenamin C, Nuka G, Pesseat S, et al. The InterPro protein families database: the classification resource after 15 years. Nucleic Acids Res. 2015; 43(D1):D213-D221

45. Lanfear R, Calcott B, Kainer D, Mayer C, Stamatakis A. Selecting optimal partitioning schemes for phylogenomic datasets. BMC Evol Biol. 2014;14(1):82

46. Stamatakis A. RAxML version 8: a tool for phylogenetic analysis and postanalysis of large phylogenies. Bioinformatics. 2014;30(9):1312-3.

47. Brown JM, EIDabaje R. PuMA: Bayesian analysis of partitioned (and unpartitioned) model adequacy. Bioinformatics. 2009;25(4):537-8.

48. Ronquist F, Teslenko M, van der Mark P, Ayres DL, Darling A, Höhna S, Larget B, Liu L, Suchard MA, Huelsenbeck JP. MrBayes 3.2: efficient Bayesian phylogenetic inference and model choice across a large model space. Syst Biol. 2012;61(3):539-42.

49. Aberer AJ, Kobert K, Stamatakis A. ExaBayes: Massively Parallel Bayesian Tree Inference for the Whole-Genome Era. Mol Biol Evol. 2014;31(10):2553-6.

50. Brown JM, Hedtke SM, Lemmon AR, Lemmon EM. When trees grow too long: investigating the causes of highly inaccurate Bayesian branch-length estimates. Syst Biol. 2010;59(2):145-61.

51. Zhang C, Rannala B, Yang Z. Robustness of compound dirichlet priors for bayesian inference of branch lengths. Syst Biol. 2012;61(5):779-84.

52. Rannala B, Zhu T, Yang Z. Tail paradox, partial identifiability, and influential priors in Bayesian branch length inference. Mol Biol Evol. 2012:29(1):325-35.

53. Wheeler WC, Lucaroni N, Hong L, Crowley LM, Varón A. POY version 5: phylogenetic analysis using dynamic homologies under multiple optimality criteria. Cladistics. 2014:31(2):189-96.

54. Giribet G, Sharma PP, Benavides LR, Boyer SL, Clouse RM, De Bivort BL, Dimitrov D, Kawauchi GY, Murienne J, Schwendinger PJ. Evolutionary and biogeographical history of an ancient and global group of arachnids (Arachnida: Opiliones: Cyphophthalmi) with a new taxonomic arrangement. Biol J Linn Soc. 2012;105(1):92-130.

55. De Laet J. A problem in POY tree searches (and its work-around) when some sequences are observed to be absent in some terminals. Cladistics. 2010;26(5):453-5.

56. Bouchard-Côté A, Sankararaman S, Jordan MI. Phylogenetic inference via sequential Monte Carlo. Syst Biol. 2012;61(4):579-93.

57. Hackett SJ, Kimball RT, Reddy S, Bowie RC, Braun EL, Braun MJ, Chojnowski JL, Cox WA, Han K-L, Harshman J. A phylogenomic study of birds reveals their evolutionary history. Science. 2008;320(5884):1763-8.

58. Lakner C, Van Der Mark P, Huelsenbeck JP, Larget B, Ronquist F. Efficiency of Markov chain Monte Carlo tree proposals in Bayesian phylogenetics. Syst Biol. 2008;57(1):86-103.

59. Tarasov SI, Solodovnikov AY. Phylogenetic analyses reveal reliable morphological markers to classify mega-diversity in Onthophagini dung beetles (Coleoptera: Scarabaeidae: Scarabaeinae). Cladistics. 2011;27(5):490-528.

60. Emlen DJ, Marangelo J, Ball B, Cunningham CW. Diversity in the weapons of sexual selection: horn evolution in the beetle genus Onthophagus (Coleoptera: Scarabaeidae). Evolution. 2005;59:1060-84.

61. Vaz-de-Mello FZ. Synopsis of the new subtribe Scatimina (Coleoptera: Scarabaeidae: Scarabaeinae: Ateuchini), with descriptions of twelve new genera and review of Genieridium, new genus. Zootaxa. 1955;2008:1-75.

62. Bollback JP. Bayesian model adequacy and choice in phylogenetics. Mol Biol Evol. 2002;19(7):1171-80.

63. Gelman A, Meng X-L, Stern H. Posterior predictive assessment of model fitness via realized discrepancies. Stat Sin. 1996;6(4):733-60.

64. Philips TK. Phylogeny of the Oniticellini and Onthophagini dung beetles (Scarabaeidae, Scarabaeinae) from morphological evidence. Zookeys. 2016;579:9.

65. Krikken J, Huijbregts J. Miniature scarabs of the genus Haroldius on Sulawesi, with notes on their relatives (Coleoptera: Scarabaeidae). Tijdschrift voor Entomologie. 2006;149(2):167-87.

66. Mlambo S, Sole CL, Scholtz CH. A molecular phylogeny of the African Scarabaeinae (Coleoptera: Scarabaeidae). Arthropod Syst Phylogeny. 2015; 73(2):303-21.

67. Balthasar V. Monographie der Scarabaeidae und Aphodiidae der palaearktischen und orientalischen Region. Tschechoslowakische Akademie der Wissenschaften Prag. 1963;1:391. XXIV pl.
68. Pereira FS. O genero Scatonomus Er. (Coleoptera, Scarabaeidae). Rev bras Ent Sao Paulo. 1954;1:53-172

69. ICZN: International Code of Zoological Nomenclature, adopted by the International Union of Biological Sciences. In.: International Trust for Zoological Nomenclature London; 1999.

70. Halffter G, Matthews EG: The natural history of dung beetles of the subfamily Scarabaeinae (Coleoptera, Scarabaeidae). Folia ent mex 1966 Nos. 12-14:1-312

\section{Submit your next manuscript to BioMed Central and we will help you at every step:}

- We accept pre-submission inquiries

- Our selector tool helps you to find the most relevant journal

- We provide round the clock customer support

- Convenient online submission

- Thorough peer review

- Inclusion in PubMed and all major indexing services

- Maximum visibility for your research

Submit your manuscript at www.biomedcentral.com/submit

) BioMed Central 